\title{
Efficacy and survival rate of intensity-modulated radiotherapy combined with chemotherapy for elderly patients with locally advanced oropharyngeal cancer
}

\author{
$\mathrm{LIFENG}^{1}$, SHUMMEI QI ${ }^{2}$ and MING LIN ${ }^{3}$ \\ ${ }^{1}$ Customer Service Management Office, Shandong University Affiliated Jinan Central Hospital, Jinan, Shandong 250013; \\ ${ }^{2}$ Department of Stomatology, Jinan Maternity and Child Health Care Hospital, Jinan, Shandong 250001; \\ ${ }^{3}$ Department of Stomatology, Shandong University Affiliated Jinan Central Hospital, Jinan, Shandong 250013, P.R. China
}

Received November 13, 2017; Accepted December 12, 2017

DOI: $10.3892 /$ etm.2017.5682

\begin{abstract}
The efficacy of intensity-modulated radiotherapy (IMRT) combined with chemotherapy in the treatment of elderly patients with locally advanced oropharyngeal cancer and its effect on survival rate were studied. Elderly patients $(n=150)$ diagnosed with locally advanced oropharyngeal cancer by histopathology were selected and randomly divided into the observation group $(n=75)$ and the control group $(n=75)$. Patients in the observation group were treated with IMRT combined with chemotherapy, while those in the control group were treated with conventional radiotherapy and chemotherapy. The two groups were treated with docetaxel + cisplatin (TP regimen). All patients received 1 to 2 cycles of docetaxel + cisplatin-induced chemotherapy, and after the radiotherapy began, the chemotherapy with docetaxel was synchronously conducted. The recent efficacy (tumor regression condition was observed at 3 months after the treatment), 1-year, 3-year and 5-year overall survival (OS), local-regional control (LRC), progression-free survival (PFS), disease-free survival (DFS) and the incidence rate of adverse reactions of patients in the two groups were compared. In the observation group, 73 patients completed the radiotherapy and chemotherapy, while all the patients in the control group completed the treatments. The 1-year OS of the observation group and the control group was 97.3 and $85.3 \%$, respectively. In the observation group, the 3-year LRC, OS, PFS and DFS of the observation group was $94.5,91.8,90.4$ and $87.7 \%$, respectively; the 5-year LRC, OS, PFS and DFS was 64.4, 56.2, 56.2 and $54.8 \%$, respectively. In the control group, the 3-year LRC, OS, PFS and DFS was 86.7, 73.3, 82.7 and $68.0 \%$, respectively; the 5-year LRC, OS, PFS and DFS were 54.7, 45.3, 44.0
\end{abstract}

Correspondence to: Dr Ming Lin, Department of Stomatology, Shandong University Affiliated Jinan Central Hospital, 105 Jiefang Road, Lixia, Jinan, Shandong 250013, P.R. China

E-mail: gm054x@163.com; linming1966@163.com

Key words: locally advanced oropharyngeal cancer, elderly, intensity-modulated radiotherapy, chemotherapy, survival rate and $56.7 \%$, respectively. The differences were statistically significant $(\mathrm{P}<0.05)$. In the observation group, the number of leukocytes was decreased, and the incidence rates of acute oropharyngeal mucosa reaction and radiation dermatitis were significantly lower than those in the control group. The differences were statistically significant $(\mathrm{P}<0.05)$. In conclusion, IMRT combined with chemotherapy can improve the OS and the 3-year and 5-year LRC, PFS and DFS of elderly patients with locally advanced oropharyngeal cancer, reduce toxic and side effects, and improve patients' quality of life.

\section{Introduction}

In recent years, oropharyngeal cancer has accounted for $\sim 1.3 \%$ of systemic malignant tumors and $4.2 \%$ of head and neck cancers. With the changes in people's eating habits and gradually increased pressure, the incidence rate continues to rise. The disease often occurs in men, especially in those aged 50-60 years or alcoholics. In addition, betel nut, human papillomavirus infection and other factors are related to the occurrence of oral cancer to a certain degree (1). At present, if the locally advanced oral cancer is only treated by surgical treatments, the specificity of its anatomical location and strong invasion will bring great difficulties to the operation, which not only causes severe postoperative trauma, but also greatly affects organ functions (2). However, if the disease is only treated with radiotherapy, the possibility of the recurrence of the disease is greater than that treated with surgery (3). In particular, if the routine radiotherapy or surgery was conducted in stage III and IV, the 5-year survival rate will be $<40 \%$.

With the promotion of intensity-modulated radiotherapy (IMRT), increasingly a comprehensive treatment, IMRT combined with chemotherapy (4-6) has been proposed. IMRT has a certain targeting ability, so it can accurately act on the tumor target region, which ensures the function of normal tissues, and optimizes the dose on the target region (7).

\section{Patients and methods}

General data. Patients (150) were numbered from 1-150 in order, and were randomly divided into the observation group 
Table I. Comparison of general data between two groups of patients.

\begin{tabular}{|c|c|c|c|c|}
\hline \multirow[b]{2}{*}{ Patient characteristics } & \multirow{2}{*}{$\begin{array}{c}\text { Observation group } \\
\mathrm{n}(\%)\end{array}$} & \multirow{2}{*}{$\begin{array}{c}\text { Control group } \\
\mathrm{n}(\%)\end{array}$} & \multicolumn{2}{|c|}{ Statistics } \\
\hline & & & $\chi^{2}$ & P-value \\
\hline No. of patients & $75(50.0)$ & $75(50.0)$ & & \\
\hline Sex & & & 0.234 & 0.772 \\
\hline Male & $63(84.0)$ & $65(87.7)$ & & \\
\hline Female & $12(16.0)$ & $10(13.3)$ & & \\
\hline Age (years) & & & 0.503 & 0.766 \\
\hline $40-60$ & $54(72.0)$ & $51(68.0)$ & & \\
\hline$>60$ & $21(28.0)$ & $24(32.0)$ & & \\
\hline Location of lesion & & & 0.266 & 0.875 \\
\hline Amygdala & $43(57.3)$ & $41(54.7)$ & & \\
\hline Root of tongue & $20(26.7)$ & $25(33.3)$ & & \\
\hline Soft palate & $12(16.0)$ & $9(12.0)$ & & \\
\hline Clinical stage & & & 0.192 & 0.741 \\
\hline Stage III & $34(45.3)$ & $40(53.3)$ & & \\
\hline Stage IV & $41(54.7)$ & $35(46.7)$ & & \\
\hline Pathological type & & & 0.258 & 0.813 \\
\hline Low-undifferentiated squamous cell carcinoma & $45(60.0$ & $41(54.7$ & & \\
\hline Moderate-high differentiated squamous cell carcinoma & $30(40.0$ & $34(45.3$ & & \\
\hline Karnofsky Performance Score (KPS) & & & 0.791 & 0.952 \\
\hline$>90$ & $48(64.0)$ & $50(66.7)$ & & \\
\hline $70-90$ & $24(32.0)$ & $23(30.7)$ & & \\
\hline$<70$ & $3(4.0)$ & $2(2.7)$ & & \\
\hline
\end{tabular}

and the control group using a computer. The implementation of treatment was conducted by following the principle of the single-blind trial. General data of two groups of patients are shown in Table I, and the differences were not statistically significant. The study was approved by the Ethics Committee of Shandong University Affiliated Jinan Central Hospital.

\section{Methods}

Inclusion criteria. i) Patients aged $\geq 40$ years; ii) patients newly diagnosed with oral cancer by pathology; iii) patients who were divided into stage III-IV according to the Union for International Cancer Control (UICC) 2010 staging system (8); iv) patients with normal lung, liver and kidney functions before the treatment; v) patients without any contraindications to radiotherapy and chemotherapy; vi) patients whose stages were clearly determined by computed tomography (CT) and magnetic resonance imaging (MRI) before operation, and patients with distant metastasis were excluded; vii) patients with no other second primary tumor; viii) patients who signed the radiotherapy informed consent.

Exclusion criteria. i) Pregnant or lactating women; ii) patients complicated with severe infection; iii) patients with a second primary tumor; iv) patients complicated with heart, lung, liver, kidney or other organic diseases.

\section{Treatment methods}

Grouping regimens. After the induction chemotherapy, two groups of patients received concurrent radiotherapy and chemotherapy. The radiotherapy method in the observation group was IMRT, and that in the control group was conventional radiotherapy.

Chemotherapy regimens. i) Induction chemotherapy: On D1, $135 \mathrm{~g} / \mathrm{m}^{2}$ docetaxel was intravenously instilled for $1 \mathrm{~h}$; on D2, cisplatin $75 \mathrm{mg} / \mathrm{m}^{2}$ was intravenously instilled for $1 \mathrm{~h}$; a cycle included 21 days, and there were 4 treatment cycles in total. ii) Concurrent chemotherapy: Patients were administered $20 \mathrm{mg} / \mathrm{m}^{2}$ once a week for 6 weeks.

To avoid an allergic reaction, patients were given $20 \mathrm{mg}$ dexamethasone at 6 and $12 \mathrm{~h}$ before administration, respectively. They took orally $50 \mathrm{mg}$ diphenhydramine and were intravenously injected with $300 \mathrm{mg}$ cimetidine at $30 \mathrm{~min}$ before administration.

$I M R T$. After the mask was fixed, the CT simulation was used to scan the images, which were transmitted to the planning system. After three-dimensional reconstruction and fusion by the three-dimensional reverse planning system, the IMRT program was formed. After the dose was verified, and the program was co-examined by physicians at three levels, the radiotherapy could be conducted.

Conventional radiotherapy. The dose was $2.12 \mathrm{~Gy} / \mathrm{frac}-$ tion/day, and the frequency was 5 times/week. The total dose was $70 \mathrm{~Gy}$. The radiotherapy was conducted for 33 times in total.

Evaluation of efficacy and adverse reactions. Evaluation of tumor depression: The Positron Emission Tomography (PET) 
Table II. Comparison of the recent efficacy.

\begin{tabular}{lrrr}
\hline Treatment efficacy & $\begin{array}{r}\text { Observation } \\
\text { group, n(\%) }\end{array}$ & $\begin{array}{c}\text { Control } \\
\text { group, n (\%) }\end{array}$ & P-value \\
\hline $\begin{array}{l}\text { Primary lesion } \\
\text { CR }\end{array}$ & $65(89.1)$ & $64(85.3)$ & 0.556 \\
PR & $8(10.9)$ & $11(14.7)$ & \\
Cervical lymph node & & & 0.248 \\
metastasis lesion & & & \\
CR & $50(71.4)$ & $52(72.2)$ & \\
PR & $20(28.6)$ & $20(27.8)$ & \\
\hline
\end{tabular}

$\mathrm{CR}$, complete remission; PR, partial remission.

Response Criteria in Solid Tumors (PERCIST) was used according to the results of imageological review at 3 months after the treatment (9). Evaluation of adverse reactions in the acute phase: The National Cancer Institute (NCI)-Common Terminology Criteria for Adverse Events (CTCAE) 4.0 was used (10). Evaluation adverse reactions in the distant phase: Criteria of Radiation Therapy Oncology Group (RTOG) and the European Organization for Research and Treatment of Cancer (EORTC) were jointly used to assess the radiation damage. According to these criteria, the adverse reactions were divided into 0 -IV degree, and toxic and side effects were recorded once a week.

Follow-up began from the time of diagnosis. At 1 year after the diagnosis, patients were followed up and reviewed once every 3 months; at 2-5 years after the diagnosis, patients were followed up and reviewed once every 6 months. Main examinations: three routine examinations, oropharynx and neck MRI, chest and abdomen CT, pharynx fiberoptic bronchoscopy. $\mathrm{T}$ [overall survival $(\mathrm{OS})]=\mathrm{T}$ (death of patients/end of follow-up) - T (diagnosis); 3-year local-regional control $($ LRC $)=$ the number of cases with no enlarged tumor confirmed by the imageological examination/the number of total cases; $\mathrm{T}$ (progression-free survival $(\mathrm{PFS})=\mathrm{T}$ (tumor recurrence/metastasis) - $\mathrm{T}$ (diagnosis); $\mathrm{T}$ [disease-free survival $(\mathrm{DFS})]=\mathrm{T}$ (no recurrence/metastasis) $-\mathrm{T}$ (end of diagnosis).

Statistical analysis. Data were processed using SPSS 21.0 (IBM, New York, NY, USA). The t-test was used to detect measurement data, $\chi^{2}$ test was used to detect enumeration data, and the Kaplan-Meier method was used to calculate the survival rate. The Kolmogorov-Smirnov (K-S) non-parametric test was used to compare the percentage. $\mathrm{P}<0.05$ represents the statistically significant difference.

\section{Results}

Completion of treatment. Seventy-three patients in the observation group completed the treatment, in which 1 patient did not complete the treatment and died, and 1 patient was lost to the follow-up. Cervical lymph node metastasis occurred in 70 patients. In the control group, all the patients completed the treatment, and cervical lymph node metastasis occurred in 72 patients.
Comparison of the recent efficacy. At 3 months after the radiotherapy, imageological examination was conducted for the two groups of patients, the primary lesion and cervical lymph node metastastatic lesions were determined, which showed that complete remission (CR) was achieved in primary lesions of 67 patients $(89.3 \%)$, and partial remission (PR) was achieved in 8 patients $(00.7 \%)$ in the observation group. CR was achieved in cervical lymph node metastasis lesions of 50 patients (70.4\%), and PR in 21 patients (29.6\%). In the control group, CR was achieved in primary lesions of 64 patients (85.3\%), and PR in 11 patients (14.7\%). CR was achieved in cervical lymph node metastasis lesions of 51 patients (72.9\%), and PR in 19 patients (27.1\%). As shown in Table II, there was no significant difference in the recent efficacy between the two groups.

Comparison of the survival rate between the two groups. In the observation group, 1-year LRC, OS, PFS and DFS was 97.3, 97.3, 95.9 and 95.9\%, respectively; 3-year LRC, OS, PFS and DFS was 94.5, 91.8, 90.4 and $87.7 \%$, respectively; 5-year LRC, OS, PFS and DFS was 64.4, 56.256 .2 and 54.8\%, respectively. In the control group, 1-year LRC, OS, PFS and DFS was 92.0, 85.3, 92.0 and 76.0\%, respectively; 3-year LRC, OS, PFS and DFS was $86.7,73.3,82.7$ and $68.0 \%$, respectively; 5-year LRC, OS, PFS and DFS was 54.7, 45.3, 44.0 and 56.7\%, respectively. The differences in 3-year and 5-year LRC, OS, PFS and DFS between the observation group and the control group were statistically significant $(\mathrm{P}<0.05$ for all comparisons), and 5-year LRC, OS, PFS and DFS were significantly decreased compared with 1-year and 3-year LRC, OS, PFS and DFS. The details of the survival rate of the two groups are shown in Table III.

Comparisons of adverse reactions. As shown in Table IV, leukocytes were decreased to different degrees in patients of the observation group and the control group during the whole treatment. The adverse reactions were mainly concentrated in the I-II degree, including oropharyngeal mucosa reaction and radiation dermatitis. The adverse reactions in the observation group were reduced compared with those in the control group ( $\mathrm{P}<0.05$ for all comparisons).

\section{Discussion}

According to the survey data over the past years, the incidence rate of oropharyngeal cancer is gradually increasing, which often occurs in the 50-60-year-old males, especially in those addicted to alcohol and tobacco (10). For oropharyngeal cancer in the stage III-IV, the difficulty of surgery is much higher, in which there will be more cancer tissues left. Therefore, the preferred choice is radiotherapy and chemotherapy, and the primary problem of radiotherapy and chemotherapy is how to kill cancer cells farthest while improving the quality of life of patients (11). Induction chemotherapy, that is, pre-radiotherapy chemotherapy, whose efficacy is not affected by radiotherapy, easily plays a role at the tumor site, improves the radiation sensitivity, eliminates subclinical lesions and improves the survival rate of patients. The side effects of radiotherapy have a great impact on the quality of life of patients. With the development and application of computer technology, the IMRT has been proposed, and side effects such as xerostomia are expected to 
Table III. Comparison of the survival rate between the two groups.

\begin{tabular}{|c|c|c|c|c|c|c|}
\hline \multirow[b]{2}{*}{ Survival rate } & \multicolumn{3}{|c|}{ Stage III } & \multicolumn{3}{|c|}{ Stage IV } \\
\hline & $\begin{array}{l}\text { Observation group } \\
\qquad(\mathrm{n}=33)\end{array}$ & $\begin{array}{l}\text { Control group } \\
\qquad(\mathrm{n}=40)\end{array}$ & P-value & $\begin{array}{l}\text { Observation group } \\
\qquad(\mathrm{n}=40)\end{array}$ & $\begin{array}{l}\text { Control group } \\
\qquad(\mathrm{n}=35)\end{array}$ & P-value \\
\hline \multicolumn{7}{|l|}{$\mathrm{LRC}, \mathrm{n}(\%)$} \\
\hline 1-year & $33(100.0)$ & $38(95.0)$ & 0.042 & $38(95.0)$ & $31(88.6)$ & 0.022 \\
\hline 3-year & $32(97.0)$ & $36(90.0)$ & 0.037 & $37(92.5)$ & $29(82.9)$ & 0.021 \\
\hline 5-year & $25(75.8)$ & $26(65.0)$ & 0.017 & $22(55.0)$ & $15(42.9)$ & 0.027 \\
\hline \multicolumn{7}{|l|}{ OS, n (\%) } \\
\hline 1-year & $32(97.0)$ & $37(92.5)$ & 0.078 & $38(95.0)$ & $27(77.1)$ & 0.019 \\
\hline 3-year & $31(94.0)$ & $30(75.0)$ & 0.011 & $36(90.0)$ & 25 (71.4) & 0.014 \\
\hline 5-year & $23(69.7)$ & $22(55.0)$ & 0.036 & $18(45.0)$ & $12(34.3)$ & 0.028 \\
\hline \multicolumn{7}{|l|}{ PFS, n (\%) } \\
\hline 1-year & $32(97.0)$ & 37 (92.5) & 0.049 & 37 (92.5) & $30(85.7)$ & 0.039 \\
\hline 3-year & $32(96.7)$ & $35(87.5)$ & 0.038 & $34(85.0)$ & $27(77.1)$ & 0.032 \\
\hline 5-year & $20(60.6)$ & $20(50.0)$ & 0.019 & $21(52.5)$ & $13(37.1)$ & 0.014 \\
\hline \multicolumn{7}{|l|}{ DFS, n (\%) } \\
\hline 1-year & $32(97.0)$ & $32(80.0)$ & 0.044 & $38(95.0)$ & $25(71.4)$ & 0.027 \\
\hline 3-year & $30(90.1)$ & $28(70)$ & 0.019 & $34(85)$ & $23(65.7)$ & 0.015 \\
\hline 5-year & $21(63.6)$ & $23(57.5)$ & 0.034 & $19(47.5)$ & $12(34.3)$ & 0.036 \\
\hline
\end{tabular}

LRC, local-regional control; OS, overall survival; PFS, progression-free survival; DFS, disease-free survival.

Table IV. Comparisons of adverse reactions between the two groups.

\begin{tabular}{|c|c|c|c|c|c|c|c|}
\hline \multirow[b]{2}{*}{ Toxic reaction } & \multicolumn{3}{|c|}{ Observation group $(n=73)$} & \multicolumn{3}{|c|}{ Control group $(n=75)$} & \multirow[b]{2}{*}{ P-value } \\
\hline & 0 & I-II & III-IV & 0 & I-II & III-IV & \\
\hline Decreased leukocytes & $\begin{array}{c}4 \\
(5.5)\end{array}$ & $\begin{array}{c}38 \\
(52.1)\end{array}$ & $\begin{array}{c}31 \\
(42.5)\end{array}$ & $\begin{array}{c}4 \\
(5.3)\end{array}$ & $\begin{array}{c}56 \\
(74.6)\end{array}$ & $\begin{array}{c}15 \\
(20.0)\end{array}$ & 0.027 \\
\hline Xerostomia & $\begin{array}{l}0 \\
0\end{array}$ & $\begin{array}{c}57 \\
(78.1)\end{array}$ & $\begin{array}{c}16 \\
(21.9)\end{array}$ & $\begin{array}{l}0 \\
0\end{array}$ & $\begin{array}{c}67 \\
(89.3)\end{array}$ & $\begin{array}{c}8 \\
(1.1)\end{array}$ & 0.018 \\
\hline Radiation dermatitis & $\begin{array}{l}0 \\
0\end{array}$ & $\begin{array}{c}49 \\
(67.1)\end{array}$ & $\begin{array}{c}24 \\
(32.9)\end{array}$ & $\begin{array}{l}0 \\
0\end{array}$ & $\begin{array}{c}55 \\
(73.3)\end{array}$ & $\begin{array}{c}20 \\
(26.7)\end{array}$ & 0.044 \\
\hline
\end{tabular}

be improved $(12,13)$. IMRT has several radiation fields, and the intensity of each sub-field can be adjusted. After precise adjustment, tumor regions are high-dose irradiation area, and the surrounding normal tissues and organs are low-dose irradiation areas, which maintain the function of normal tissues and organs to the maximum degree and improve the quality of life of patients while improving the LRC of tumor (7). In this study, the difference in efficacy between IMRT and radiotherapy combined with chemotherapy is emphasized. The results showed that both the 1-year and 3-year LRC in the observation group were higher than those in the control group, and the same is true in the toxic and side effects, which are consistent with the study findings of Huang et al (14) and Daly et al (15).

In order to reduce the random error, the patients were randomly divided into groups using a computer in this study. In the course of treatment, only the researchers knew the treatment plan, but the patients themselves did not know the plan, which reduced the influence of their subjective consciousness on the data collection in the experiment, thus making the follow-up more reliable. Although the impact of subjective awareness of the researchers on test results was not reduced, the safety of patients in the test was ensured. In the comparison of the survival rate, staging was conducted for patients to compare the difference in the survival rate between the observation group and the control group. Except the differences in a few indicators between the two groups they were not statistically significant, other significant differences suggested that the efficacy of the observation group is better than that of the control group. However, since there were 33 patients in stage III and 40 patients in stage IV in the control group, and there were 40 patients in stage III and 35 patients in stage IV, 
the test results were not universal, so in order to study the effect of staging on the survival rate, the number of study objects should be increased. In view of the fact that the second primary tumor exerts an unknown detrimental effect on the long-term efficacy, patients with a second primary tumor were excluded during inclusion so as to make the results comparable (16).

There are many regimens for induction chemotherapy. Vermorken et al (17) believed that the efficacy of docetaxel + cisplatin +5 -fluorouracil $(\mathrm{TPF})$ regimen (docetaxel + cisplatin +5 -fluorouracil docetaxel + cisplatin +5 -fluorouracil) for induction chemotherapy is increased compared with that of the cisplatin + 5-fluorouracil (PF regimen); Rosenthal et al (18) proposed the concurrent platinum-based chemotherapy. The super-segmented IMRT has also been put forward, it combines the advantages of super-grading with those of IMRT. The study of Monnerat et al (16) showed the feasibility of this regimen, but stage II tests are still needed to validate its efficacy (19). The assessment of survival and adverse reactions was limited by only using the criteria of the World Health Organization (WHO), Response Evaluation Criteria In Solid Tumors (RECIST) and RECIST 1.1, especially when assessing the efficacy of newer cancer treatments. These criteria needed to be further revised and enhanced after being verified by various diseases and treatments (20). Hoeller et al (21) argued that the late effects of normal tissue-subjective, objective, management, and analytic (LENT-SOMA) scoring system is superior to the RTOG criteria, so we need to consider optimizing the LENT/SOMA scoring system, thus making the report on advanced radioactive morbidity rate more standardized (21). Differently, the latest study of Kelly et al (22) revealed that the treatment regimen not modulated by intensity can be applied to reduce the occurrence of side effects, such as reducing radiation dose and replacing radiation-sensitive chemotherapy.

In conclusion, IMRT combined with chemotherapy can be used to improve the OS of elderly patients with locally advanced oropharyngeal cancer, 3-year and 5-year LRC, PFS and DFS, reduce side effects and improve patients' quality of life.

\section{References}

1. Pinar T, Akdur R, Tuncbilek A, Altundag K and Cengiz M: The relationship between occupations and head and neck cancers. J Natl Med Assoc 99: 64, 68-71, 2007.

2. Harréus U: Surgical errors and risks - the head and neck cancer patient. GMS Curr Top Otorhinolaryngol Head Neck Surg 12: Doc04, 2013.

3. Kaplan EL: Postoperative irradiation with or without concomitant chemotherapy for locally advanced head and neck cancer. N Engl J Med 9: 133-134, 2005.

4. Miah AB, Schick U, Bhide SA, Guerrero-Urbano MT, Clark CH, Bidmead AM, Bodla S, Del Rosario L, Thway K, Wilson P, et al: A phase II trial of induction chemotherapy and chemo-IMRT for head and neck squamous cell cancers at risk of bilateral nodal spread: The application of a bilateral superficial lobe parotid-sparing IMRT technique and treatment outcomes. Br J Cancer 112: 32-38, 2015.

5. Nutting C, Harrington K, Rogers MS, Sydenham MA, A'Hern R and Hall M: Results of a phase III multi-centre randomised controlled trial of intensity modulated (IMRT) vs. conventional radiotherapy (RT) in head and neck cancer (PARSPORT: ISRCTN48243537; CRUK/03/005). Clin Oncol 22: 899, 2009.

6. Monroe AT, Young JA, Ernster JA, Huff JD and Peddada AV: Acute toxicity of concomitant boost IMRT and chemotherapy for gead and neck cancer in the community setting. Int J Radiat Oncol Biol Phys 72: S413, 2008.
7. Nutting CM, Morden JP, Harrington KJ, Urbano TG, Bhide SA, Clark C, Miles EA, Miah AB, Newbold K, Tanay M, et al; PARSPORT trial management group: Parotid-sparing intensity modulated versus conventional radiotherapy in head and neck cancer (PARSPORT): A phase 3 multicentre randomised controlled trial. Lancet Oncol 12: 127-136, 2011.

8. Kreppel M, Eich HT, Kübler A, Zöller JE and Scheer M: Prognostic value of the sixth edition of the UICC's TNM classification and stage grouping for oral cancer. J Surg Oncol 102: 443-449, 2010

9. Yanagawa M, Tatsumi M, Miyata H, Morii E, Tomiyama N, Watabe T, Isohashi K, Kato H, Shimosegawa E, Yamasaki M, et al: Evaluation of response to neoadjuvant chemotherapy for esophageal cancer: PET response criteria in solid tumors versus response evaluation criteria in solid tumors. J Nucl Med 53: 872-880, 2012.

10. Chen AP, Setser A, Anadkat MJ, Cotliar J, Olsen EA, Garden BC and Lacouture ME: Grading dermatologic adverse events of cancer treatments: The Common Terminology Criteria for Adverse Events version 4.0. J Am Acad Dermatol 67: 1025-1039, 2012.

11. Clavel S, Nguyen DH, Fortin B, Després P, Khaouam N, Donath D, Soulières D, Guertin L and Nguyen-Tan PF: Simultaneous integrated boost using intensity-modulated radiotherapy compared with conventional radiotherapy in patients treated with concurrent carboplatin and 5-fluorouracil for locally advanced oropharyngeal carcinoma. Int J Radiat Oncol Biol Phys 82: 582-589, 2012.

12. Parliament M, Alidrisi M, Munroe M, Wolfaardt J, Scrimger R, Thompson H, Field C, Kurien E and Hanson J: Implications of radiation dosimetry of the mandible in patients with carcinomas of the oral cavity and nasopharynx treated with intensity modulated radiation therapy. Int J Oral Maxillofac Surg 34: 114-121, 2005.

13. Yao M, Dornfeld KJ, Buatti JM, Skwarchuk M, Tan H, Nguyen T, Wacha J, Bayouth JE, Funk GF, Smith RB, et al: Intensitymodulated radiation treatment for head-and-neck squamous cell carcinoma - the University of Iowa experience. Int J Radiat Oncol Biol Phys 63: 410-421, 2005.

14. Huang K, Xia P, Chuang C, Weinberg V, Glastonbury CM, Eisele DW, Lee NY, Yom SS, Phillips TL and Quivey JM: Intensity-modulated chemoradiation for treatment of stage III and IV oropharyngeal carcinoma: The University of California-San Francisco experience. Cancer 113: 497-507, 2008.

15. Daly ME, Le QT, Maxim PG, Loo BW Jr, Kaplan MJ, Fischbein NJ, Pinto H and Chang DT: Intensity-modulated radiotherapy in the treatment of oropharyngeal cancer: Clinical outcomes and patterns of failure. Int J Radiat Oncol Biol Phys 76: 1339-1346, 2010.

16. Monnerat C, Faivre S, Temam S, Bourhis J and Raymond E: End points for new agents in induction chemotherapy for locally advanced head and neck cancers. Ann Oncol 13: 995-1006, 2002.

17. Vermorken JB, Remenar E, van Herpen C, Gorlia T, Mesia R, Degardin M, Stewart JS, Jelic S, Betka J, Preiss JH, et al; EORTC 24971/TAX 323 Study Group: Cisplatin, fluorouracil, and docetaxel in unresectable head and neck cancer. N Engl J Med 357: 1695-1704, 2007.

18. Rosenthal DI, Harris J, Forastiere AA, Weber RS, Ridge JA, Myers JN, Garden AS, Kuettel MR, Sidhu K, Schultz CJ, et al: Early postoperative paclitaxel followed by concurrent paclitaxel and cisplatin with radiation therapy for patients with resected high-risk head and neck squamous cell carcinoma: Report of the phase II trial RTOG 0024. J Clin Oncol 27: 4727-4732, 2009.

19. Balukrishna S, Pilaka VKR, Michael RC, Samuel P and Ravindran PB: Hyper-fractionated intensity modulated radiation therapy (HF-IMRT) in head and neck cancer: The technical feasibility and results of a short clinical series. J Clin Diagn Res 9: XR01-XR04, 2015.

20. Wahl RL, Jacene H, Kasamon Y and Lodge MA: From RECIST to PERCIST: Evolving considerations for PET response criteria in solid tumors. J Nucl Med 50 (Suppl 1): 122S-150S, 2009.

21. Hoeller U, Tribius S, Kuhlmey A, Grader K, Fehlauer F and Alberti W: Increasing the rate of late toxicity by changing the score? A comparison of RTOG/EORTC and LENT/SOMA scores. Int J Radiat Oncol Biol Phys 55: 1013-1018, 2003.

22. Kelly JR, Husain ZA and Burtness B: Treatment de-intensification strategies for head and neck cancer. Eur J Cancer 68: 125-133, 2016.

This work is licensed under a Creative Commons Attribution-NonCommercial-NoDerivatives 4.0 International (CC BY-NC-ND 4.0) License. 